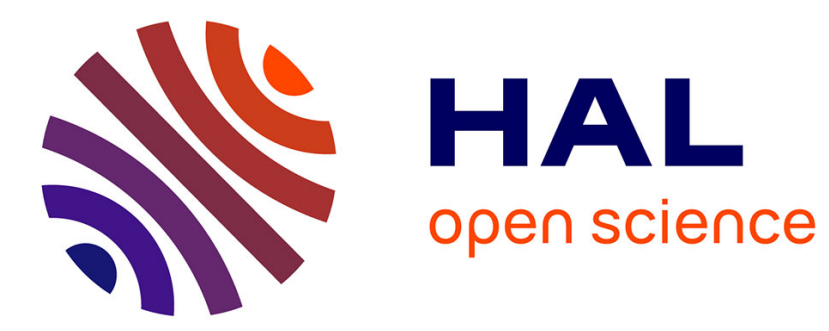

\title{
Local Order in Hydrogenated Amorphous Germanium Thin Films
}

G. Dalba, P. Fornasini, C. Graeff, R. Grisenti, F. Rocca, A. Traverse

\section{To cite this version:}

G. Dalba, P. Fornasini, C. Graeff, R. Grisenti, F. Rocca, et al.. Local Order in Hydrogenated Amorphous Germanium Thin Films. Journal de Physique IV Proceedings, 1997, 7 (C2), pp.C2-1013-C21014. 10.1051/jp4:19972121 . jpa-00255180

\section{HAL Id: jpa-00255180 https://hal.science/jpa-00255180}

Submitted on 1 Jan 1997

HAL is a multi-disciplinary open access archive for the deposit and dissemination of scientific research documents, whether they are published or not. The documents may come from teaching and research institutions in France or abroad, or from public or private research centers.
L'archive ouverte pluridisciplinaire HAL, est destinée au dépôt et à la diffusion de documents scientifiques de niveau recherche, publiés ou non, émanant des établissements d'enseignement et de recherche français ou étrangers, des laboratoires publics ou privés. 


\title{
Local Order in Hydrogenated Amorphous Germanium Thin Films
}

\author{
G. Dalba, P. Fornasini, C. Graeff*, R. Grisenti, F. Rocca** and A. Traverse*** \\ INFM and Dipartimento di Fìsica dell'Università di Trento, 38050 Povo di Trento, Italy \\ *.Walter Schottky Insitut, Technische Universitaet Muenchen 85748 Garching, Germany \\ ** Centro CNR-ITC Cefsa, 38050 Povo di Trento, Italy \\ *** LURE, Bât. 209D, 91405 Orsay cedex, France
}

\begin{abstract}
The effect of the hydrogenation process on the local order in amorphous germanium has been studied by EXAFS spectroscopy. Measurements have been carried out on amorphous sputtered $\mathrm{Ge}: \mathrm{H}$ films with 7,10 and 15 at. \% hydrogen concentration, as function of temperature from 11 to $300 \mathrm{~K}$. The EXAFS data analysis has been carried out by the cumulant method and the first four cumulants of the first shell distance distributions have been extracted. The temperature dependence of cumulants gives information on dynamic local disorder and allows the quantitative determination of the influence of hydrogenation on static disorder. It is confirmed that the amorphous non-hydrogenated films are more disordered than the hydrogenated ones. Small but significant differences in the cumulants have been observed as function of the hydrogen content; they show that the larger the concentration the more ordered the germanium network. The first shell distribution functions have been reconstructed for the hydrogenated samples and compared with that of the non hydrogenated compound.
\end{abstract}

\section{Introduction}

The objective of this work is to study the role of hydrogen on the short range order of some amorphous films of hydrogenated germanium. Hydrogen plays a fundamental role in the optoelectronic and structural properties of tetrahedrally bonded amorphous semiconductors: $\mathrm{H}$ atoms remove some of weak bonds and passivate dangling orbitals, relaxing the structure and improving the electronic properties. Hydrogen is also thought to be intrinsically connected with the metastability effects observed either in a-Si:H and a-Ge:H. It is usually accepted that the local structure of a-Ge:H is predominantly that of a disordered tetrahedrally coordinated network. It is also known that the incorporation of $\mathrm{H}$ in amounts of the order of 10 at. \% influences the network connectivity and reduces the amount of point defects. However there is only a relatively poor quantitative knowledge about the short range order in terms of bonding length, static and thermal disorder and asymmetry of the first shell distance distribution function.

The EXAFS technique has been already applied to study a-Ge:H [1], in its standard formulation based on the harmonic approximation. This approach provided original information and rectified some conclusions obtained by $\mathrm{X}$ ray scattering about the first shell coordination of Ge, however, its limits when applied to amorphous systems are now well known. The present work is a study as a function of temperature of the EXAFS at the $\mathrm{K}$ edge of Ge by cumulant method which goes beyond the harmonic approximation. The temperature dependence allows to monitor the thermal behaviour of the parameters which describe the first shell distributions and to separate thermal and static contributions to the mean square relative displacements. In the following we outline the essential data about the experimental procedures then we present and discuss the experimental results.

\section{Experimental}

The a-Ge(:H) samples were deposited on a $3 \mu \mathrm{m}$ Al foil by r.f. sputtering a pure crystalline Ge target in an atmosphere of Ar mixed with $10 \%$ hydrogen partial pressure in the case of the hydrogenated compounds. The EXAFS measurements were carried out at the D $42 \mathrm{D}$ experimental station at the L.U.R.E. laboratories in Orsay, in transmission mode, up to a transferred momentum $k=20 \AA^{\cdot}$; a very large signal to noise ratio was obtained for all the samples even at the highest $k$. The details on the data analysis are the same reported in ref. [2]. For extracting the structural results from experimental data the phase difference and ratio amplitude methods were utilized; the EXAFS of the crystalline Ge at the lowest temperature was used as a reference for phase shifts and backscattering amplitudes.

\section{Results and discussion}

Table 1 summarizes the results at room temperature of the first four cumulants of the first shell distance distribution for the a-Ge $(: H)$ samples; some other data present in the literature are reported for comparison. The estimation of the error bars is based on the results of the analysis procedure with different conditions. The first cumulant $\Delta \mathrm{C}_{1}$ coincides with the difference $\Delta R=R_{a-G e(: H)}-R_{c-G e}$ between the mean value of the first shell distance distribution of amorphous and crystalline samples. $C_{2}$ represents the Mean Square Relative Displacement (MSRD) $\sigma^{2} ; \Delta \mathrm{C}_{2}=\mathrm{C}_{2}$ a-Ge(:H) $(\mathrm{T})-\mathrm{C}_{2} \mathrm{c}$-Ge $(11 \mathrm{~K}$ ) is the difference between the MSRD of the amorphous film and the $c-G e$ at $11 \mathrm{~K} . \mathrm{C}_{3}$ and $\mathrm{C}_{4}$ are the first anharmonic terms of distance distributions. 
The $\Delta \mathrm{R}$ obtained by the cumulant expansion of EXAFS, independently of the $\mathrm{H}$ concentration, are comprised between 0.018 and $0.020 \AA$, indicating that the mean interatomic distance in a-Ge(:H) is larger than in c-Ge. The only EXAFS data for hydrogenated samples present in the literature [1] give lower $\Delta \mathrm{R}$ (table 1) perhaps owing to the use of the standard analysis method; our results for the amorphous non-hydrogenated sample agree with the results obtained by XRD (0.0204 $\AA$ ) [3] and by most recent EXAFS measurements [4]. As for the Debye-Waller factor, $\Delta \sigma^{2}$, the present work confirms that the hydrogenation process has a positive influence on the local order as already found by Bouldin et al. [1] (table 1); however the percentage reduction of $\Delta \sigma^{2}$ recorded in ref. [1] is larger than that found in the present work. Table 1 shows that the absolute values of $\Delta \sigma^{2}$ found by the cumulant method are quite different than those obtained by the EXAFS standard analysis procedure [1], however, as for the non hydrogenated samples, the $\Delta \sigma^{2}$ value of the present work is comparable to the values determined in ref. [4] for a-Ge sputtered films and in ref. [2] for evaporated films. The extent of static disorder in the a-Ge(:H) films has been determined by comparing, at low temperature, the $\sigma^{2}(T)$ of the amorphous compounds with the $\sigma^{2}(T)$ of $c-G e$ : it is equal to $1.9310^{-3} \AA^{2}$ for the non hydrogenated film and to $1.70 \AA^{2}$ for the 15 at. \% hydrogenated film. In Fig. 1 the first shell distribution functions of the a-Ge(:H) samples reconstructed by the first four cumulants are compared with the one of the a-Ge: a significant increase in the ordering in the first shell, function of the $H$ content, is shown by the differences $\rho_{a-G e}$ minus $\rho_{\mathrm{a}-\mathrm{Ge}: \mathrm{H}}$ Our measurements for the coordination number change $\Delta \mathrm{N} / \mathrm{N}$ are consistent with the conclusion [1] that the hydrogenated samples have a first shell coordination number that is indistinguishable from the crystal within the experimental error.

In conclusion we measure a small but significant increase of the ordering which is function of the $\mathrm{H}$ content. However the addition of $\mathrm{H}$ in a-Ge does not sensitively modify first shell mean distance and coordination number suggesting that the hydrogens are mainly bound to the surfaces of the internal voids of a-Ge.

Table I

\begin{tabular}{|c|c|c|c|c|c|}
\hline Sample & $\begin{array}{l}\Delta \mathrm{R} \\
(\AA)\end{array}$ & $\begin{array}{c}\Delta \sigma^{2} \\
\left(10^{-3} \AA^{2}\right)\end{array}$ & $\begin{array}{c}C_{3} \\
\times 10^{-4} \AA^{3} \\
\end{array}$ & $\begin{array}{c}C_{4} \\
\times 10^{-6} \AA^{4} \\
\end{array}$ & ref. \\
\hline a-Ge sputtered & $0.019 \pm 0.005$ & $3.71 \pm 0.30$ & $1.12 \pm 0.50$ & $2.7 \pm 0.13$ & present \\
\hline " & 0.019 & 2.0 (ref. @ $300 \mathrm{~K}$ ) & 1.15 & & [4] \\
\hline$"$ & $0.003(2)$ & $1.63(10)$ & & & [1] \\
\hline a-Ge evaporated & $0.018 \pm 0.005$ & $4.47 \pm 0.40$ & $1.07 \pm 0.42$ & $3.52 \pm 0.15$ & [2] \\
\hline a-Ge 7 at $\%$ & $0.018 \pm 0.005$ & $3.64 \pm 0.30$ & $1.06 \pm 0.42$ & $4.6 \pm 0.2$ & present \\
\hline a-Ge 10 at $\%$ & $0.019 \pm 0.005$ & $3.48 \pm 0.30$ & $1.04 \pm 0.42$ & $3 \pm 0.15$ & $"$ \\
\hline a-Ge 15 at $\%$ & $0.020 \pm 0.005$ & $3.54 \pm 0.30$ & $1.04 \pm 0.42$ & $3.9 \pm 0.2$ & $"$ \\
\hline $\mathrm{a}-\mathrm{Ge} 4.9$ at $\%$ & $0.00(2)$ & $1.40(10)$ & & & [1] \\
\hline a-Ge 6 at $\%$ & $0.006(2)$ & $1.10(10)$ & & & [1] \\
\hline
\end{tabular}

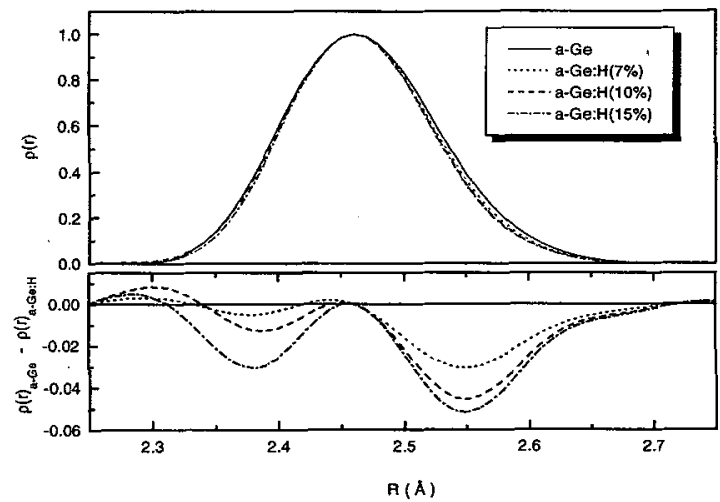

Fig. 1 First shell distance distributions $\rho(r)$ for a-Ge(:H) thin films (upper part).

Difference $\rho_{\text {a.Ge }}(r)-\rho_{\text {n.Ge:H }}(r)$ between the distance distribution of a-Ge and the ones of the hydrogenated compounds (lower part).

\section{References}

[1] C. E. Bouldin, E. A. Stern, B. von Roedern, J. Azoulay, Phys. Rev. B 30, 4462, (1984).

[2] G. Dalba, P. Fornasini, M. Grazioli, F. Rocca, Phys. Rev. B 52, 11034 (1995).

[3] R. J. Temkin, W. Paul and G.A. N. Connel Adv. Phys. 22, 581 (1973).

[4] M. Wakagi and Y. Maeda, Phys. Rev. B 50, 14090 (1994). 